\title{
Atipia de Células Glandulares em Esfregaços do Colo do Útero: Avaliação dos Métodos Propedêuticos
}

\author{
Atypical Glandular Cells in Cervical Smear: Analysis of Diagnostic Methods \\ Luiz Antonio Verdiani ${ }^{1}$, Sophie Françoise Mauricette Derchain ${ }^{1}$ \\ Marcelo Schweller ${ }^{2}$, Renata Clementino Gontijo ${ }^{1}$ \\ Liliana Aparecida Angelo Andrade ${ }^{2}$, Luiz Carlos Zeferino ${ }^{1}$
}

\begin{abstract}
RESUM0
Objetivo: avaliar a propedêutica em mulheres com atipias de células glandulares no resultado colpocitológico.

Pacientes e Métodos: foram avaliadas prospectivamente 159 mulheres atendidas por resultado citológico de atipias de células glandulares, entre janeiro e dezembro de 2000. Todas foram submetidas a coleta de nova colpocitologia e a colposcopia. Foi realizada biópsia dirigida em 50 casos, curetagem endocervical em 21 e conização em 75. O desempenho dos métodos propedêuticos foi descrito por estimativas de sensibilidade, especificidade, valores preditivos e razão de verossimilhanças, tendo como padrão-ouro o resultado histológico.

Resultados: entre as 51 mulheres que apresentaram neoplasia intra-epitelial escamosa, 29 foram de baixo grau e 22 de alto grau. Cinco mulheres apresentaram adenocarcinoma in situ e seis, neoplasias invasoras. Isoladamente, a sensibilidade e a especificidade da colpocitologia foram respectivamente 88,5 e 39\%, e da colposcopia, 74 e 42\%. A associação da colposcopia com a colpocitologia elevou a sensibilidade para 98,4\%, com queda da especificidade para 10\%. A curetagem endocervical apresentou sensibilidade muito baixa (25\%).

Conclusão: a presença de atipias glandulares na colpocitologia relacionou-se com lesões cervicais pré-neoplásicas e neoplásicas em 62,2\% dos casos submetidos a avaliação histológica. A repetição da citologia e a colposcopia permitiram selecionar as mulheres que se beneficiaram com a avaliação histológica. A conização mostrou-se adequada quando os exames mantiveram alterações morfológicas.
\end{abstract}

PALAVRAS-CHAVE: Colpocitologia. Atipia glandular. Colo do útero: lesões pré-neoplásicas. Colo do útero: câncer.

\section{Introdução}

A colpocitologia oncológica é o método de eleição no rastreamento do câncer do colo do útero. Em 1988, os membros da Sociedade Americana de Citopatologia reuniram-se em Bethesda (EUA)

${ }^{1}$ Departamento de Tocoginecologia e ${ }^{2}$ Departamento de Anatomia Patológica da Faculdade de Ciência Médicas da Universidade Estadual de Campinas (UNICAMP)

Correspondência:

Sophie F. M. Derchain

Rua Antonio Hossri, 629 - Cidade Universitária

13.083-370 - Campinas - SP

Fone: (19) 3788-9305/ Fax: (19) 32895935

e-mail: derchain@supernet.com.br

Órgãos financiadores: FAPESP (99/05598-2) e CNPq (300354/01-0) e introduziram a classificação denominada "Sistema de Bethesda", com o propósito de estabelecer terminologia uniforme para o diagnóstico das amostras citológicas. Um dos objetivos desse sistema foi estabelecer critérios mais específicos na determinação das atipias celulares. Nesta classificação, novas categorias diagnósticas foram estabelecidas, incluindo as atipias de células glandulares de significado indeterminado ${ }^{1-3}$.

A categoria de atipias de células glandulares de significado indeterminado foi definida como a presença de células com diferenciação endometrial ou endocervical apresentando atipias nucleares que excedem processos reacionais ou reparativos óbvios, mas não chegam a apresentar características inequívocas de adenocarcinoma 
invasor. Os esfregaços com atipias de células glandulares representam apenas pequena porcentagem dos diagnósticos citológicos, cerca de 0,1 a $1,8 \%{ }^{4-8}$. Comparada com a neoplasia cervical escamosa, a neoplasia glandular cervical é bem menos freqüente, embora muitos autores tenham demonstrado aumento da incidência de adenocarcinoma in situ e de adenocarcinoma invasor. Este aumento aparente das lesões glandulares pode ser devido ao aumento da detecção das formas pré-invasoras, pela maior divulgação da necessidade de coleta de material endocervical quando da realização da colpocitologia oncológica e, por outro lado, pela diminuição na incidência do carcinoma escamoso do colo, o que gera um aumento proporcional das lesões glandulares ${ }^{9-11}$. A história natural da neoplasia glandular é pouco conhecida e ainda existem dúvidas quanto à existência e à evolução das lesões precursoras do adenocarcinoma invasor. Se o adenocarcinoma in situ do colo uterino é hoje aceito como precursor do adenocarcinoma invasor, a relação entre as atipias glandulares endocervicais indeterminadas e adenocarcinoma invasor permanece controversa ${ }^{12}$.

No Brasil, após a Campanha do Ministério da Saúde ${ }^{13}$ e da Secretaria da Saúde do Estado de São Paulo ${ }^{14}$, houve aumento significativo de mulheres submetidas à coleta de citologia com escova endocervical nos programas de controle de câncer do colo uterino, com conseqüente aumento do número de casos de atipias de células glandulares. O Laboratório de Citopatologia do Centro de Atenção Integral à Saúde da Mulher (CAISM) é responsável pela leitura de mais de 200.000 exames colpocitológicos por ano e o Ambulatório de Patologia Cervical deste hospital está equipado para o diagnóstico e tratamento das lesões do colo uterino. Assim, o objetivo deste estudo foi selecionar grande número de mulheres com diagnóstico colpocitológico de atipias de células glandulares endocervicais para avaliar, de forma prospectiva, a propedêutica a ser utilizada.

\section{Pacientes e Métodos}

Para este estudo de corte transversal e validação de teste diagnóstico, foram selecionadas as mulheres com resultado de colpocitologia oncológica compativel com atipias de células glandulares entre aqueles lidos pelo laboratório de Citopatologia do CAISM de janeiro a dezembro de 2000. O projeto foi aprovado pelo Comitê de Ética em Pesquisa da Faculdade de Ciências Médicas da UNICAMP. Entre as 217.245 lâminas avaliadas pelo laboratório neste período, $443(0,2 \%)$ apresen- tavam atipias de células glandulares sem outras especificações. Até o final deste estudo, haviam sido enviadas cartas de convocação para $297 \mathrm{mu}-$ lheres, das quais 163 compareceram ao atendimento no serviço entre fevereiro de 2000 e junho de 2001. Destas, 159 satisfizeram os critérios de inclusão e aceitaram fazer parte da pesquisa após consentimento livre e esclarecido. As mulheres foram submetidas a exame clínico cuidadoso com inspeção dos genitais externos e região perianal. A seguir, uma espátula de Ayre e uma escova endocervical foram utilizadas para coleta de material da ectocérvice e da endocérvice para nova colpocitologia oncológica. Finalmente, foi realizada uma colposcopia empregando-se o ácido acético a $3 \%$, com observação de toda a zona de transformação e, quando pertinente, biópsia dirigida por colposcopia das regiões alteradas. Todas as mulheres foram submetidas a exame ultra-sonográfico de pelve e abdome para avaliação do endométrio e ovários.

Nos primeiros casos foi realizada curetagem endocervical com cureta de Novak. A curetagem endocervical é citada como método propedêutico em vários estudos referentes a atipias de células glandulares, e optou-se por realizar este estudo piloto em 21 casos para avaliação do seu desempenho. A conização uterina foi realizada nas seguintes circunstâncias: ausência de lesões suspeitas à colposcopia ou colposcopia insatisfatória com pelo menos dois resultados citológicos adequadamente coletados e fixados sugestivos de atipia celular endocervical; resultado de biópsia sugestivo de NIC 2 ou 3 e discordância entre a citologia e a biópsia dirigida por colposcopia. Neste estudo, das 75 mulheres submetidas a conização, a técnica utilizada foi o cone a bisturi frio em 5 mulheres e a conização por cirurgia de alta freqüência com alça larga em 70. A avaliação histológica foi realizada pelo Departamento de Anatomia Patológica da Faculdade de Ciências Médicas, UNICAMP.

Entre as 159 mulheres incluídas no estudo, 57 apresentaram resultado da colpocitologia coletada no serviço sem alterações suspeitas ou neoplásicas e colposcopia normal. Assim, estas mulheres não foram submetidas a avaliação histológica e após duas citologias negativas coletadas com intervalos de quatro meses, foram consideradas sem doença e reencaminhadas aos serviços de origem.

Entre as mulheres submetidas a avaliação histológica, foi mensurado o desempenho da colpocitologia, curetagem e colposcopia, por estimativas de sensibilidade, especificidade, valores preditivos positivo e negativo e razão de verossimilhanças, sendo considerado como padrão-ouro 
o resultado histológico final. A presença de doença no resultado anatomopatológico, desde NIC 1 / HPV até neoplasias invasoras, foi utilizada para caracterização deste desempenho. Foi considerado o nível de significância estatística de 5\%. Na análise estatística, utilizou-se o programa SAS de microcomputador, versão 8.0.

\section{Resultados}

Das 159 pacientes estudadas, 102 foram submetidas a avaliação histológica, entre biópsia e conização. O resultado mais grave entre estes dois foi considerado o resultado histológico final. Trinta e uma mulheres apresentaram cervicite ou metaplasia escamosa sem atipias. Uma paciente apresentou adenofibroma do colo uterino. Entre as mulheres que apresentaram algum tipo de lesão neoplásica, pré-invasora ou invasora na histologia, observamos 51 lesões escamosas, sendo 29 casos compativeis com lesões de baixo grau (HPV/NIC 1) e 22 casos compativeis com lesão de alto grau (NIC 2 ou 3). Cinco mulheres apresentaram adenocarcinoma in situ, e seis, neoplasias invasoras, sendo dois adenocarcinomas, dois carcinomas escamosos, um adenocarcinoma de endométrio associado com NIC 3 e um adenocarcinoma metastático da vesícula biliar associado com NIC 3 (Tabela 1).

Tabela 1 - Distribuição das 159 mulheres segundo o resultado histológico final (biópsia dirigida por colposcopia e/ou cone).

\begin{tabular}{lcc}
\hline Resultado histológico & Número & Porcentagem (\%) \\
\hline Sem exame anatomopatológico & 57 & 35,8 \\
Cervicite ou metaplasia & 31 & 19,5 \\
Pólipo endocervical & 7 & 4,4 \\
Pólipo endometrial & 1 & 0,6 \\
Adenofibroma & 1 & 0,6 \\
NIC 1 ou HPV & 29 & 18,2 \\
NIC 2 ou 3 & 22 & 13,8 \\
Adenocarcinoma in situ & 5 & 3,1 \\
Adenocarcinoma & 2 & 1,3 \\
Carcinoma escamoso & 2 & 1,3 \\
NIC 3 com adenocarcinoma & 1 & 0,6 \\
$\quad$ de endometriol & & \\
NIC 3 com adenocarcinoma & 1 & 0,6 \\
$\quad$ metastático & & \\
Total & 159 & 100,0 \\
\hline
\end{tabular}

$\mathrm{Na}$ avaliação do resultado da colpocitologia coletada no serviço observamos que, entre as 159 mulheres avaliadas, $43(27 \%)$ mantiveram atipias de células glandulares no resultado citológico. Trinta mulheres apresentaram alterações esca- mosas, sendo 10 classificadas como atipias de células escamosas de origem indeterminada (ASCUS) e 20 classificadas como NIC. Quatro pacientes apresentaram resultados sugestivos de adenocarcinoma in situ e duas de carcinoma escamoso invasor. Mais da metade das mulheres $(50,3 \%)$ apresentaram esfregaços citológicos com alterações inflamatórias, sem atipia. Todas as mulheres foram submetidas à colposcopia pelo mesmo examinador. A colposcopia foi satisfatória em $90 \%$ das pacientes, entretanto não foi possivel a visualização da junção escamocolunar em 16 mulheres. Entre as mulheres com colposcopia satisfatória, $79(55,2 \%)$ apresentavam colposcopia normal e $64(44,7 \%)$ apresentavam imagens suspeitas (Tabela 2). Todas as pacientes com citologia alterada (79) e mais 23 com citologia inflamatória, mas com alterações colposcópicas, foram submetidas à avaliação histológica. Cinqüenta e sete mulheres, sem evidência de doença na citologia do serviço e na colposcopia, foram submetidas a seguimento com colposcopia e citologia a cada quatro meses até dois exames negativos (dados não apresentados em tabela).

Ainda na Tabela 2, observa-se que, quando a colpocitologia foi compativel com alterações inflamatórias, a maioria das mulheres apresentou resultado histológico compativel com lesão escamosa de baixo grau, NIC 1 ou alteração citopática compativel com infecção pelo HPV. Entretanto, duas mulheres com resultado inflamatório na colpocitologia do serviço apresentavam lesão escamosa intra-epitelial de alto grau (NIC 2 ou 3). Das 43 mulheres cuja colpocitologia coletada no serviço apresentou alterações compativeis com atipias de células glandulares, 15 apresentaram apenas cervicite na avaliação histológica, porém oito apresentaram lesão de alto grau (NIC 2 ou 3), uma apresentou adenocarcinoma in situe outra apresentou carcinoma escamoso invasor. Entre as mulheres com resultado citológico do serviço compativel com ASCUS ou NIC, a maioria apresentava lesão de células escamosas, entretanto uma paciente apresentou adenocarcinoma in situ e outra adenocarcinoma endometrial associado a NIC 3 na avaliação histológica. Quatro mulheres apresentaram colpocitologia sugestiva de adenocarcinoma in situ, sendo duas confirmadas pela histologia e outras duas resultando em adenocarcinomas invasores. Nas duas pacientes com citologia de neoplasias invasoras confirmouse a presença de câncer cervical.

Quando comparamos o resultado da colposcopia com o resultado histológico, observamos que entre as mulheres com colposcopia normal houve um caso de adenocarcinoma invasor, um caso de adenocarcinoma in situ e dois com le- 
são escamosa de alto grau, NIC 2 ou 3. Entre as 64 mulheres com colposcopia anormal, 17 apresentaram NIC 2 ou 3, quatro apresentaram adenocarcinoma in situ e cinco neoplasias invasoras. Entre as mulheres com colposcopia insuficiente, três apresentaram NIC 2 ou 3.

A curetagem endocervical foi realizada em 21 mulheres. Dessas, 16 apresentaram resultado considerado normal, 15 com mucosa endocervical e uma com mucosa endometrial. Em três pacientes foram identificadas atipias celulares, sendo duas com lesões escamosas de alto grau (NIC 2 ou 3) e outra com atipias de dificil avaliação. Em outras duas o material foi escasso ou inadequado para diagnóstico. Quando comparado com o diagnóstico final, observamos que a curetagem endocervical apresentou seis resultados falso-negativos e um resultado falso-positivo. Um caso cujo diagnóstico histológico final foi adenocarcinoma in situ não apresentava alterações morfológicas no material da curetagem; em dois casos de NIC 2 ou 3 o material da curetagem foi inadequado para diagnóstico ou apresentou apenas mucosa endometrial. Por outro lado, um caso apresentou atipias inconclusivas no material da curetagem e não demonstrou alterações pré-neoplásicas ou neoplásicas ao cone (dados não apresentados em tabela).

Na Tabela 3 pode ser avaliado o desempenho da colpocitologia, colposcopia e da curetagem endocervical. A colpocitologia coletada no serviço apresentou 7 falso-negativos, e 25 falso-positivos. Apresentou sensibilidade de $88,5 \%$, mas especificidade de apenas 39\%. Isoladamente, a colposcopia apresentou desempenho ruim, com 15 resultados falso-negativos e 19 falso-positivos. A sensibilidade da colposcopia foi de $74 \%$ e a especificidade de $42,4 \%$. Quando se avaliou o desempenho da associação entre colposcopia e citologia, observou-se que ocorreu grande aumento na sensibilidade, que passou a ser $98,4 \%$, mas diminuiu-se a especificidade para $10 \%$. Finalmente, a curetagem endocervical apresentou sensibilidade muito baixa, de $25 \%$.

Tabela 2 - Distribuição das 102 mulheres com o resultado histológico final segundo o resultado da colpocitologia, da colposcopia e da curetagem endocervical.

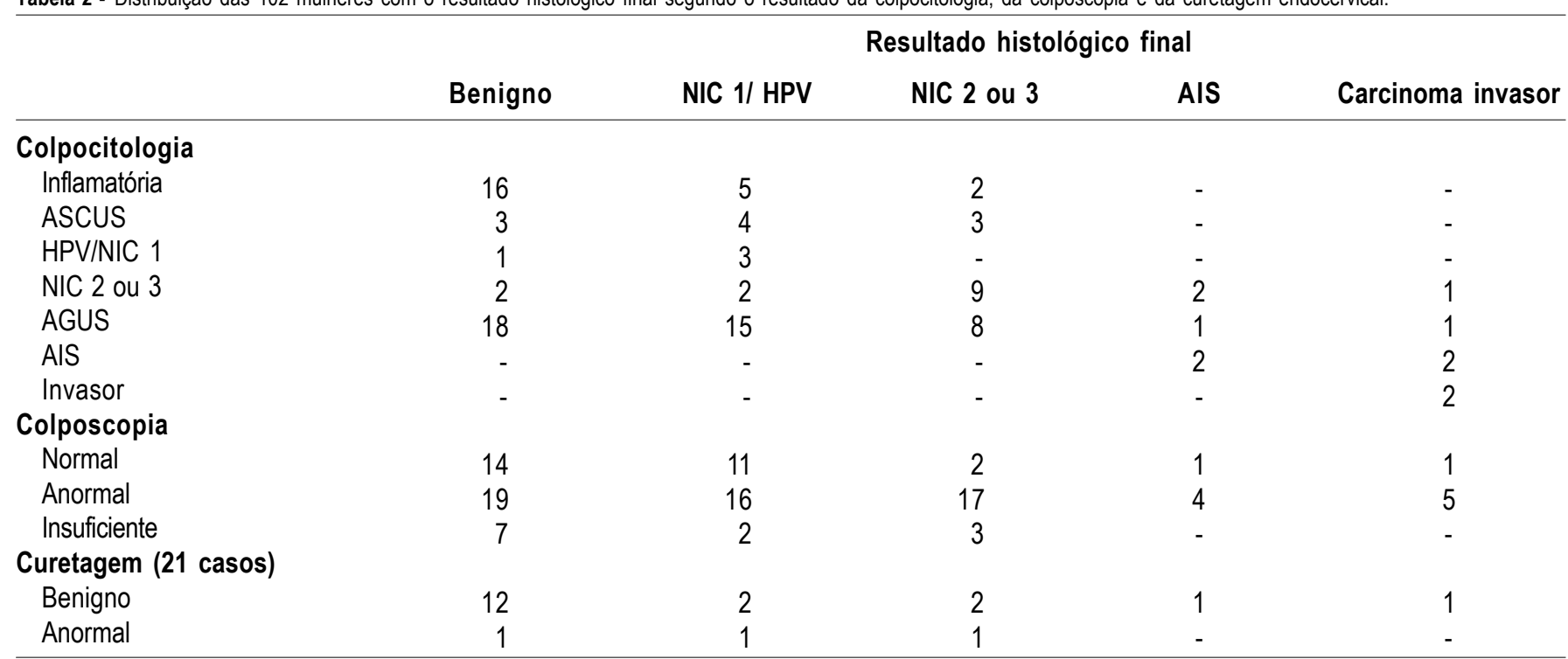

AIS = adenocarcinoma in situ; AGUS = células glandulares atipicas .

ASCUS = células escamosas de significado indeterminado.

Tabela 3 - Desempenho da colpocitologia, colposcopia, associação entre colposcopia/citologia e curetagem endocervical no diagnóstico das lesões cervicais.

\begin{tabular}{lrrrrrrrrr}
\hline & \multicolumn{3}{c}{ Histologia positiva } & \multicolumn{2}{c}{ Histologia negativa } & Sens & Esp & RV + & RV - \\
Método & VP & FN & VN & FP & \% & $\%$ & & \\
\hline Colpocitologia (102 casos) & 54 & 7 & 16 & 25 & 88,5 & 39 & 1,450 & 0,294 \\
Colposcopia (90 casos) & 42 & 15 & 14 & 19 & 74 & 42 & 1,280 & 0,620 \\
Colposcopia/citologia (102 casos) & 61 & 1 & 4 & 36 & 98,4 & 10 & 1,090 & 0,161 \\
Curetagem (21 casos) & 2 & 6 & 12 & 1 & 25 & 92 & 3,250 & 0,812
\end{tabular}

Colposcopia*= Excluindo 12 casos com avaliação histológica mas com colposcopia insuficiente VP = verdadeiro positivo; FN = falso-negativo; VN = verdadeiro negativo; FP = falsopositivo; Sens = sensibilidade; Esp = especificidade; RV+ = razão de verossimilhanças positiva; RV- = razão de verossimilhanças negativa. 
A conização cervical foi realizada em 75 mulheres e dessas, 21 (26\%) apresentaram pólipo, cervicite ou metaplasia escamosa sem atipias. Entre as mulheres com alterações neoplásicas invasoras ou pré-invasoras observamos que 26 (33\%) apresentaram lesão de baixo grau (NIC 1/ HPV), 21 (29\%) apresentaram lesão de alto grau (NIC 2 ou 3) e quatro (6\%) apresentaram adenocarcinoma in situ. Três mulheres apresentaram neoplasia invasora $(4 \%)$, sendo dois adenocarcinomas e um carcinoma escamoso.

Entre as 75 mulheres submetidas a conização, 25 foram submetidas a biópsia colpodirigida prévia. Quando comparamos o resultado da biópsia com o diagnóstico do cone, observamos que três pacientes com resultado de cervicite na biópsia apresentavam NIC 2 ou 3 no cone e que uma mulher que apresentou adenocarcinoma in situ na biópsia apresentava NIC 3 residual no cone (Tabela 4 ).

Tabela 4 - Distribuição das mulheres submetidas a conização com ou sem biópsia prévia.

Resultado histopatológico do cone

Resultado histopatológico da biópsia

Pólipo/cervicite HPV ou NIC 1 NIC 2 ou NIC 3 AIS Suspeita de invasor Sem biópsia

Pólipo/cervicite

HPV ou NIC 1

NIC 2 ou NIC 3

AIS

Carcinoma invasor

TOTAL

2
4
3
-
-
9

$2 \quad 2$

3

1

-

6

2
1
4
-
1
8

AIS = adenocarcinoma in situ

\section{Discussão}

Desde sua introdução, mesmo após a revisão do sistema Bethesda em 1994 e 2001, o diagnóstico citológico de atipias glandulares representa, para os ginecologistas, dificuldades tanto em relação à propedêutica como ao tratamento ${ }^{1-5}$. A preocupação maior reside em não submeter uma mulher a procedimentos muito agressivos como conização ou até histerectomia por uma alteração que pode ser manifestação de várias condições benignas. Por outro lado, a associação da atipia glandular com lesões neoplásicas é freqüente e pode ser grave 4,7-8 $^{\text {. Assim, os autores }}$ concordam que as pacientes com diagnóstico de atipias de células glandulares necessitam de seguimento cuidadoso ${ }^{15-18}$, sendo que alguns consideram a necessidade de colposcopia, curetagem endocervical, biópsia colpodirigida ou conização em todos os $\operatorname{casos}^{7,15-17,19-21}$.

Este estudo mostrou que a presença de atipias glandulares em resultado colpocitológico necessita de investigação propedêutica criteriosa. Assim como muitas mulheres apresentaram apenas uma alteração citológica que não se repetiu em segundo exame e não caracterizou nenhuma anormalidade cervical, outras tiveram alterações graves como adenocarcinoma in situ ou câncer invasor que somente foram diagnosticadas ao cone. Já é conhecida a associação entre a presença de atipias de células glandulares endocervicais no esfregaço citológico com alta porcentagem de lesões neoplásicas e pré-neoplásicas, podendo ser encontradas lesões graves em até metade dos casos (Tabela 5), incluindo desde atipias escamosas até neoplasias invasoras ${ }^{4-}$ 6,10,12,15-18,20,22-25.

Pelo estudo destas 159 mulheres portadoras de atipias glandulares pode-se constatar que a presença de alterações histológicas mais graves confirmou-se em mais de um terço dos casos. Embora as alterações histológicas encontradas não tenham sido sempre de natureza glandular, como sugeria o exame, pudemos constatar que o diagnóstico citológico foi indicador de lesão cervical em quase metade das mulheres que mantiveram alterações morfológicas citológicas ou na colposcopia. As atipias de células glandulares encontradas no exame citológico estiveram relacionadas com amplo espectro de lesões de diversas linhagens celulares uterinas. Pudemos observar desde alterações inflamatórias, reacionais ou reparativas, até neoplasias invasoras escamosas, glandulares, endometriais e metastática.

Optamos por repetir a coleta de colpocitologia e realizar avaliação do colo com colposcopia na primeira consulta. As mulheres que apresentaram o resultado da citologia e da colposcopia normal foram acompanhadas até a segunda citologia. Uma vez que os dois exames apresentaram resultados normais e satisfatórios, a paciente pôde ser acompanhada com segurança, sem a necessidade de realização de propedêutica mais agressiva. 
Tabela 5 - Achados histológicos em mulheres atendidas por atipias de células glandulares de significado indeterminado no exame colpocitológico, segundo diversos autores.

\begin{tabular}{|c|c|c|c|c|c|}
\hline Autor (ano) & Número total de mulheres & NIC & AIS & Câncer cervical invasor & Câncer não cervical \\
\hline Goff et al. (1992) & 100 & 17 & 5 & 2 & - \\
\hline Lee et al. $(1995)^{17}$ & 40 & 14 & 1 & - & - \\
\hline Kennedy et al. $(1996)^{22}$ & 77 & 4 & 5 & 3 & - \\
\hline Zweizig et al. (1997) & 127 & 6 & 1 & 4 & 6 \\
\hline Duska et al. (1998)12 & 81 & 16 & - & 1 & 5 \\
\hline Korn et al. $(1998)^{24}$ & 47 & 9 & 1 & 3 & 2 \\
\hline Cheng et al. $(1999)^{5}$ & 108 & 12 & 2 & 1 & 3 \\
\hline Kim et al. $(1999)^{23}$ & 326 & 24 & 5 & 7 & 13 \\
\hline Ronnett et al. (1999) ${ }^{18}$ & 137 & 12 & 5 & 1 & - \\
\hline Chin et al. $(2000)^{10}$ & 141 & 26 & 3 & - & 5 \\
\hline Chhieng et al. $(2000)^{6}$ & 133 & 26 & - & - & 7 \\
\hline Soofer e Sidawy $(2000)^{25}$ & 69 & 8 & 4 & 2 & - \\
\hline
\end{tabular}

AIS = adenocarcinoma in situ

Ainda em relação à colpocitologia coletada no serviço, observou-se que quase um terço das mulheres manteve o resultado de atipias de células glandulares. Por outro lado, um pouco mais de $20 \%$ das mulheres apresentou alterações glandulares mais graves ou alterações de células escamosas na segunda citologia. Isso mostra que, se nenhuma lesão significativa é encontrada em mais de metade das mulheres, alterações cervicais neoplásicas ou pré-neoplásicas graves e endocervicais são achado freqüente.

O objetivo de incluir a curetagem endocervical na propedêutica inicial foi avaliar seu desempenho para dirigir a propedêutica subseqüente. Porém, o material obtido pela curetagem não contribuiu de maneira significativa para o diagnóstico, motivo pelo qual decidimos pela suspensão de sua realização.

Já a biópsia foi geralmente realizada quando houve alteração colposcópica em área definida, e isso aumentou a sensibilidade do método. Uma vez que a amostra de tecido vai ser retirada de local que já não apresenta características normais, a chance de obter resultado positivo é claramente maior. Entretanto, observamos que, em alguns casos, a biópsia foi realizada em local do colo com alterações inflamatórias, sendo que a lesão pré-neoplásica somente foi diagnosticada pelo cone. Outro aspecto importante foi que, em alguns casos de doenças graves, a colposcopia mostrou-se normal, portanto sem local para realização da biópsia. Observamos que a biópsia apresentou limitações sérias em casos de doença endocervical e resultado negativo na biópsia não excluiu a possibilidade de lesão endocervical em mulheres que apresentaram atipias glandulares persistentes na citologia. Assim, a propedêutica não deve ser interrompida caso persistam alterações citológicas, mesmo na presença de colposcopia normal e biópsia negativa.

A conização, além de ampliar a área amostrada, é indicada classicamente quando a biópsia já mostrou alteração histológica ou quando a alteração citológica se mantém. A conização é método mais agressivo quando comparado à biópsia, necessitando de anestesia local ou regional e mais sujeita a complicações imediatas ou tardias, embora estas complicações não tenham sido observadas nesta casuística. Neste estudo, mais da metade dos cones foram indicados e realizados sem biópsia prévia e em quase $90 \%$ dos casos foram realizados com o uso de cirurgia de alta freqüência com alça, em ambulatório, com anestesia cervical. A cirurgia de alta freqüência com alça teve boa aceitação, sendo importante lembrar, entretanto, que existe alguma controvérsia na utilização da cirurgia diatérmica em lesões glandulares, devido ao possível artefato de margens, gerando assim dificuldades em se considerar o cone terapêutico.

Podemos concluir que, embora mais de metade das mulheres atendidas por presença de atipia de células glandulares no esfregaço cervical apresentassem apenas alterações inflamatórias na colpocitologia do serviço, proporção significativa dessas mulheres manteve resultados anormais, incluindo neoplasias invasoras. A prevalência de neoplasias intra-epiteliais cervicais de origem escamosa na avaliação histopatológica foi alta, mas também foram encontrados cinco casos de adenocarcinoma in situ e seis neoplasias invasoras, tanto escamosas como glandulares. A colposcopia foi satisfatória na maioria das pacientes e mostrou-se normal em metade da população 
estudada. A curetagem endocervical apresentouse insatisfatória como método propedêutico neste estudo. A biópsia colpodirigida subestimou a gravidade da lesão cervical em 9 dos 25 casos submetidos a biópsia seguida de cone, sendo que a conização em pacientes com atipias de células glandulares mostrou-se excelente método propedêutico em mulheres com alterações citológicas persistentes, com ou sem imagem colposcópica suspeita.

\section{ABSTRACT}

Purpose: to evaluate the diagnostic procedures used in women with Pap smear result of atypical glandular cells. Patients and Methods: a prospective study with 159 women with atypical glandular cells was carried out between January and December 2000. All women were submitted to a new colpocytology and to colposcopy. Directed biopsy was performed in 50 cases, endocervical curettage in 21 and conization in 75 . The performance of the diagnostic procedures was described by estimating the sensitivity, specificity, predictive values and likelihood ratio, considering histological results as gold standard.

Results: the histological evaluation showed 51 intraepithelial squamous lesions, 29 low grade and 22 high grade. Five women presented in situ adenocarcinoma and six patients presented invasive neoplasias. Colpocytology alone showed sensitivity and specificity of 88.5 and $39 \%$, respectively, and colposcopy alone, 74 and $42 \%$. The association of colpocytology with colposcopy increased the sensitivity to $98.4 \%$, with a significantly lower specificity of $10 \%$. Endocervical curettage showed low sensitivity (25\%).

Conclusion: the presence of atypical glandular cells on colpocytology was associated with preinvasive and invasive cervical lesions in $62.2 \%$ of the cases with histological evaluation. Repeating colpocytology and performing colposcopy allowed to select the women who needed histological evaluation. Conization was an adequate procedure when examination continued to show morphologic alterations.

KEYWORDS: Colpocytology. Glandular atypia. Uterine cervix: neoplasia.

\section{Referências}

1. Bose S, Kannan V, Kline TS. Abnormal endocervical cells. Really abnormal? Really endocervical? Am J Clin Pathol 1994; 101:708-13.

2. Kurman RJ, Solomon D. The Bethesda System for reporting cervical/vaginal cytologic diagnosis. $1^{\text {st }}$ ed. New York: Springer-Verlag; 1994. p.81.
3. The 1988 Bethesda System for Reporting Cervical/ Vaginal Cytologic Diagnoses. Developed and approved at a National Cancer Institute Workshop, Bethesda, Maryland, USA, December 12-13, 1988. J Reprod Med 1989; 34:779-85.

4. Burja IT, Thompson SK, Sawyer WL Jr, Shurbaji MS. Atypical glandular cells of undetermined significance on cervical smears. A study with cytohistologic correlation. Acta Cytol 1999; 43:351-6.

5. Cheng RF, Hernandez E, Anderson LL, Heller PB, Shank R. Clinical significance of a cytologic diagnosis of atypical glandular cells of undetermined significance. J Reprod Med 1999; 44:922-8.

6. Chhieng DC, Elgert PA, Cangiarella JF, Cohen JM. Clinical significance of atypical glandular cells of undetermined significance. A follow-up study from an academic medical center. Acta Cytol 2000; 44:557-66.

7. Goldstein NS, Ahmad E, Hussain M, Hankin RC, Perez-Reyes N. Endocervical glandular atypia: does a preneoplastic lesion of adenocarcinoma in situ exist? Am J Clin Pathol 1998; 110:200-9.

8. Kaferle JE, Maloiun JM. Evaluation and management of the AGUS Papanicolaou smear. Am Fam Physician 2001; 63:2239-44.

9. Chhieng DC, Elgert PA, Cohen JM, Cangiarella JF. Clinical significance of atypical glandular cells of undetermined significance in postmenopausal women. Cancer 2001; 93:1-7.

10.Chin AB, Bristow RE, Korst LM, Walts A, Lagasse LD. The significance of atypical glandular cells on routine cervical cytologic testing in a communitybased population. Am J Obstet Gynecol 2000; 182:1278-82.

11. Crowther ME. Is the nature of cervical carcinoma changing in young women? Obstet Gynecol Surv 1994; 50:71-82.

12.Duska LR, Flynn CF, Chen A, Whall-Strojwas D, Goodman A. Clinical evaluation of atypical glandular cells of undetermined significance on cervical cytology. Obstet Gynecol 1998; 91:278-82.

13. Ministério da Saúde. Secretaria de Políticas de Saúde. Programa Nacional de Combate ao Câncer de Colo Uterino. Núcleo de Coordenação Nacional. Programa Nacional de Combate ao Câncer: diretrizes básicas para a organização do programa. Brasília; 1998. p.1-5.

14.Secretaria de Estado da Saúde de São Paulo. Estratégia para redução da mortalidade por câncer de colo de útero no Estado de São Paulo. São Paulo; 1998. p.1-16.

15.Eddy GL, Strumpf KB, Wojtowycz MA, Piraino PS, Mazur MT. Biopsy findings in five hundred thirtyone patients with atypical glandular cells of uncertain significance as defined by the Bethesda system. Am J Obstet Gynecol 1997; 177:1188-95. 
16. Goff BA, Atanasoff P, Brown E, Muntz HG, Bell DA, Rice LW. Endocervical glandular atypia in Papanicolaou smears. Obstet Gynecol 1992; 79:101-4.

17.Lee KR, Manna EA, St John T. Atypical endocervical glandular cells: accuracy of cytologic diagnosis. Diagn Cytopathol 1995; 13:202-8.

18. Ronnett BM, Manos MM, Ransley JE, et al. Atypical glandular cells of undetermined significance (AGUS): cytopathologic features, histopathologic results and human papillomavirus DNA detection. Hum Pathol 1999; 30:816-25.

19.Parazzini F, LaVecchia C. Epidemiology of adenocarcinoma of the cervix. Gynecol Oncol 1990; 39:40-6.

20.Zweizig S, Noller K, Reale F, Collis S, Resseguie L. Neoplasia associated with atypical glandular cells of undetermined significance on cervical cytology. Gynecol Oncol 1997; 65:314-8.

21.Kisner HJ. The gray zone. Clin Lab Manage Rev 1998; 12:277-80.
22.Kennedy AW, Salmieri SS, Wirth SL, Biscotti CV, Tuason LJ, Travarca MJ. Results of the clinical evaluation of atypical glandular cells of undetermined significance (AGCUS) detected on cervical cytology screening. Gynecol Oncol 1996; 63:14-8

23.Kim TJ, Kim HS, Park CT, et al. Clinical evaluation of follow-up methods and results of atypical glandular cells of undetermined significance (AGUS) detected on cervicovaginal Pap smears. Gynecol Oncol 1999; 73:292-8.

24.Korn AP, Judson PL, Zaloudek CJ. Importance of atypical glandular cells of uncertain significance in cervical cytologic smears. J Reprod Med 1998; 43:774-8

25. Soofer SB, Sidawy MK. Atypical glandular cells of undetermined significance: clinically significant lesions and means of patient follow-up. Cancer 2000; 90:207-14

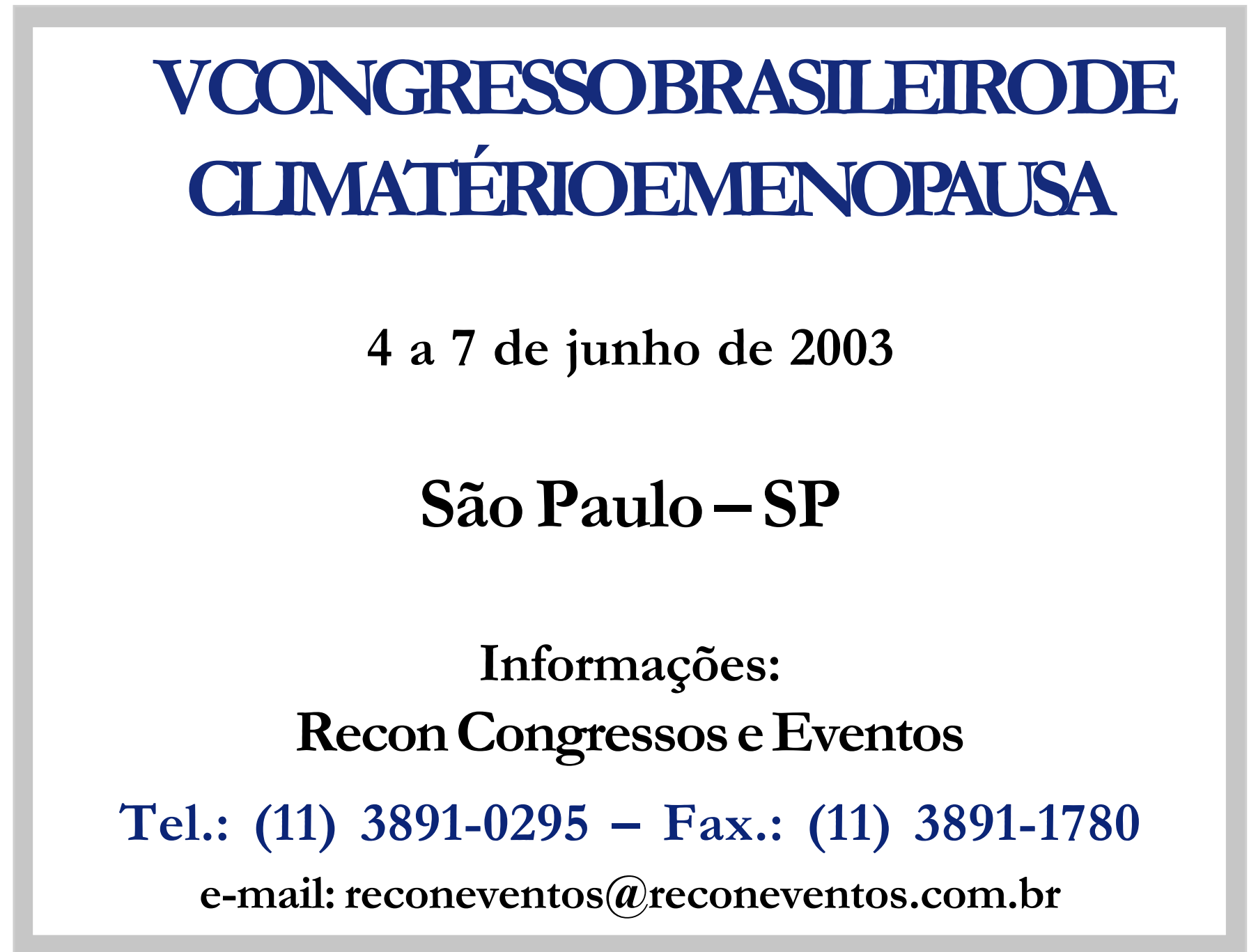

